\title{
Virulence factors in environmental and clinical Vibrio cholerae from endemic areas in Kenya
}

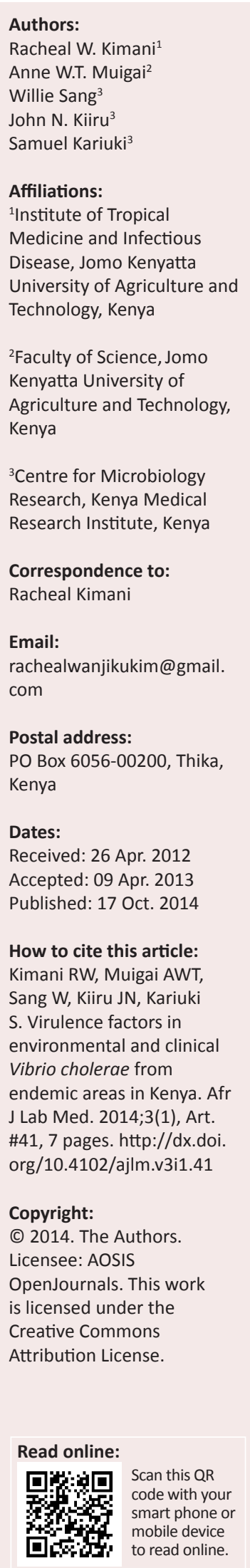

Background: Since 1971, Kenya has had repeated cholera outbreaks. However, the cause of seasonal epidemics of cholera is not fully understood and neither are the factors that drive epidemics, both in Kenya and globally.

Objectives: The objectives of the study were to determine the environmental reservoirs of $V$. cholerae during an interepidemic period in Kenya and to characterise their virulence factors.

Methods: One hundred (50 clinical, 50 environmental) samples were tested for $V$. cholerae isolates using both simplex and multiplex polymerase chain reaction.

Results: Both sediments and algae from fishing and landing bays yielded isolates of $V$. cholerae. Clinical strains were characterised along with the environmental strains for comparison. All clinical strains harboured $c t x A, t c p A$ (El Tor), ompU, zot, ace, toxR, hylA (El Tor) and tcpI genes. Prevalence for virulence genes in environmental strains was hylA (El Tor) (10\%), toxR (24\%), zot (22\%), ctxA (12\%), tcpI (8\%), hylA (26\%) and tcpA (12\%).

Conclusion: The study sites, including landing bays and beaches, contained environmental $V$. cholerae, suggesting that these may be reservoirs for frequent epidemics. Improved hygiene and fish-handling techniques will be important in reducing the persistence of reservoirs.

\section{Introduction}

Since 1971, Kenya has suffered repeated cholera outbreaks. From 1974 to 1989, outbreaks were reported every year with an average case fatality rate of 3.6\%. ${ }^{1}$ More cases have been reported in Kenya since 2005 and an outbreak in 2007 had a case fatality of up to 5.6\%. ${ }^{2}$ In 2011, 60 cholera cases, including 10 laboratory-confirmed cases and one refugee death, were reported in the world's largest refugee camp in Dadaab, Kenya. ${ }^{3}$

Significant advances have been made in understanding the molecular basis of Vibrio cholerae pathogenicity, including the identification of environmental reservoirs for the microorganism. ${ }^{4}$ It has also been shown that a 7th cholera pandemic spread from the Bay of Bengal in at least three independent but overlapping waves with a common ancestor in the 1950s and several transcontinental transmission events have been identified. ${ }^{5}$ The main reservoirs of $V$. cholerae are humans and aquatic sources such as brackish water and estuaries. ${ }^{6}$ Ahmed et al. ${ }^{7}$ showed that multiple genetic lineages of $V$. cholerae were simultaneously infecting persons in Kenya. This finding is consistent with the simultaneous emergence of multiple distinct genetic lineages of $V$. cholerae from endemic environmental reservoirs rather than recent introduction and spread by travelers. However, the cause of seasonal epidemics of cholera is not fully understood and neither are the factors that drive epidemics, both in Kenya and globally. The objectives of this study were to determine the environmental reservoirs of $V$. cholera during an interepidemic period in Kenya and to characterise their virulence factors.

\section{Research method and design}

The study was conducted in the coastal and western regions of Kenya from February 2010 to November 2010. The coastal region sampling points were distributed in the cholera-endemic districts of Kwale, Malindi, Mombasa and Kilifi (Figure 1). At each sampling point, preference was given to watering points and where there was human activity, as recommended by local health officials. The western region sampling points included the districts of Kisumu, Siaya, Rachuonyo, Homa Bay, Nandi Hills, Nyando, Bondo, Vihiga and Busia. One sample of water, zooplankton, phytoplankton, sediments and/or floating vegetation was collected at each site as available, using the method described by Huq et al. ${ }^{8}$

Isolation began on the first day after collection of the environmental samples. One $\mathrm{mL}$ each of the zooplankton and phytoplankton homogenates was enriched in $10 \mathrm{~mL}(1 \mathrm{X})$ alkaline peptone 
water. Ten $\mathrm{mL}$ of each plant homogenate and sediment sample were also enriched in $5 \mathrm{~mL}$ triple-strength alkaline peptone water. On the second day, subculturing was done from the previous day's alkaline peptone water inoculates on plates of thiosulphate citrate bile salts (TCBS). On day three, the presence of yellow mucoid colonies was considered presumptive for $V$. cholerae.

Presumptive colonies were tested by measuring their reaction to an oxidase reagent ( $1 \%$ dimethyl-p-phenylenediamine dihydrochloride), along with other biochemical tests (Voges Proskauer, Indole and carbohydrate fermentation). The environmental strains agglutinated with polyvalent $\mathrm{O}$ antisera and were sucrose fermenters. They formed large yellow mucoid colonies on the TCBS. Colonies were also gram stained to confirm the morphological characteristics of the isolates.

\section{Detection of virulence factors from environmental and clinical $V$. cholerae}

Archived clinical isolates were sampled from the Kenya Medical Research Institute (KEMRI) laboratory. These isolates were mostly from outbreaks which occurred in the years 2009-2010. Systematic random sampling was carried out in order to choose clinical strains. From a list of whole population strain numbers, a random strain number was chosen as the start strain. Thereafter, every third strain from the whole population was sampled until a total of 50 samples were chosen, which is equal to the number of environmental strains.

\section{Amplification}

Deoxyribonucleic acid (DNA) was isolated from freshlycultured environmental and clinical $V$. cholerae isolates. The

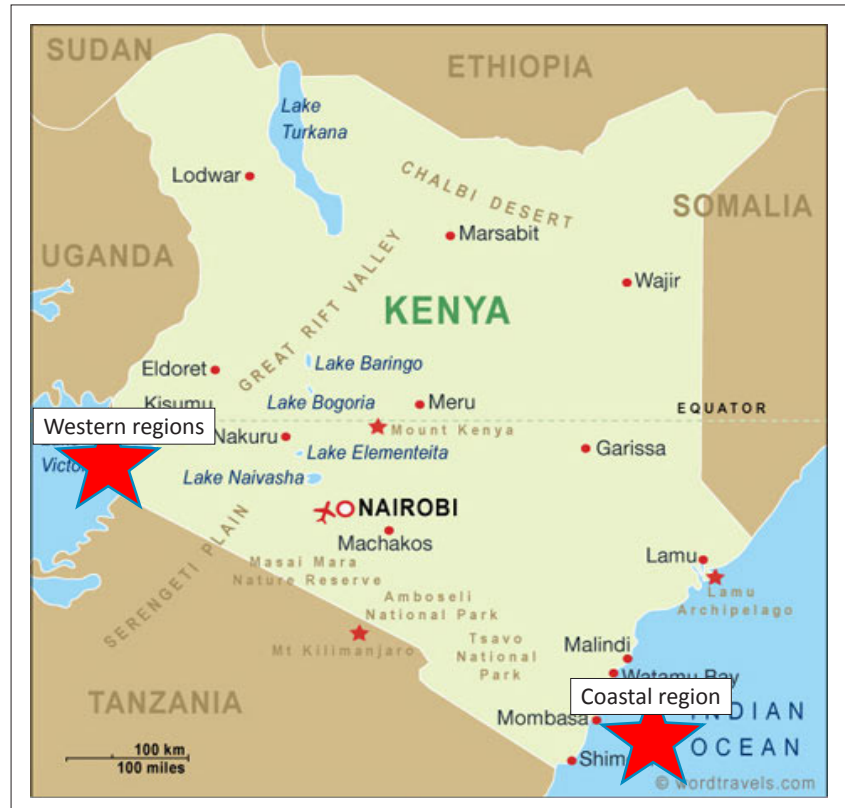

Source: Google Earth (accessed 2011 May 26)

FIGURE 1: Coastal and western regions of Kenya where environmental samples were collected. protocol was as follows: on the first day, bacterial isolates were grown at $37{ }^{\circ} \mathrm{C}$ overnight in Mueller-Hinton plates. Cells were harvested and suspended in distilled water on the second day. The suspension was heated in a water bath at $95{ }^{\circ} \mathrm{C}$ for five minutes to lyse the cells. This was then centrifuged at $14000 \mathrm{x}$ f for six minutes in order to remove the protein debris. A sample supernatant was then stored at $-20{ }^{\circ} \mathrm{C}$ for further use. Polymerase chain reaction (PCR) was performed in a total volume of $32 \mu \mathrm{L}$ containing $5 \mu \mathrm{L}$ ( $5 \mathrm{ng} / \mu \mathrm{L})$ of DNA template, $1.0 \mu \mathrm{L}(0.1 \mathrm{mM})$ each of forward and reverse primers, Healthcare Mastermix (GE Healthcare, $\mathrm{UK}$ ) and $25 \mu \mathrm{L}$ nuclease-free water.

All strains were then screened for the presence of genes encoding virulence determinants in $V$. cholerae including cholera toxin $(\operatorname{ct} x A)$, zonula occludens toxin (zot), accessory cholera enterotoxin (ace), haemolysin ( $h l y A)$, and NAGspecific heat-stable toxin (st). Detection of the $t c p A$ gene specific to the El Tor and Classical biotypes was performed using a common forward primer and biotype-specific reverse primers. Similarly, two forward primers were used for the detection of the biotype-specific haemolysin gene (hylA). PCR conditions and primers used for the detection of tcp A, ompU, tcpI, toxR and hylA genes were similar to those described previously by Rivera et al. ${ }^{9}$ (Table 1 and Table 2), whilst detection of the $\operatorname{ct} x A$ gene was done using primers and conditions described before by Fields et al. ${ }^{10}$ All PCR assays were performed using an automated Dynax thermal cycler. PCR products were analysed by electrophoresis on $1.5 \%$ agarose gels, stained with ethidium bromide, visualised under UV light and recorded with the aid of a geldocumentation system.

TABLE 1: Primers used in the study.

\begin{tabular}{|c|c|c|c|}
\hline Primer & Sequence 5'-3' & $\begin{array}{l}\text { Amplicon size } \\
\text { in bp }\end{array}$ & Reference \\
\hline ctxA-F & CGGGCAGATTCTAGACCTCCTG & \multirow[t]{2}{*}{564} & \multirow{2}{*}{$\begin{array}{l}\text { Fields et al. } \\
1992^{10}\end{array}$} \\
\hline ctxA-R & CGATGATCTTGGAGCATTCCCAC & & \\
\hline$z o t-\mathrm{F}$ & TCGCTTAACGATGGCGCGTTTTT & \multirow[t]{2}{*}{947} & \multirow{2}{*}{$\begin{array}{l}\text { Rivera et al. } \\
2001^{9}\end{array}$} \\
\hline$z o t-R$ & AACCCCGTTTCACTTCTACCCA & & \\
\hline ace- $\mathrm{F}$ & TAAGGATGTGCTTATGATGGACACCC & \multirow[t]{2}{*}{289} & \multirow{2}{*}{$\begin{array}{l}\text { Shi et al. } \\
1998^{21}\end{array}$} \\
\hline ace- $\mathrm{R}$ & CGTGATGAATAAAGATACTCATATAGG & & \\
\hline$s t-\mathrm{F}$ & GAGAAACCTATTCATTGC & \multirow[t]{2}{*}{216} & \multirow{2}{*}{$\begin{array}{l}\text { Vicente et al. } \\
1997^{22}\end{array}$} \\
\hline$s t-\mathrm{R}$ & GCAAGCTGGATTGCAAC & & \\
\hline ompU-F & ACGCTGACGGAATCAACCAAAG & \multirow[t]{2}{*}{869} & \multirow{2}{*}{$\begin{array}{l}\text { Rivera et al. } \\
2001^{9}\end{array}$} \\
\hline ompU-R & GCGGAAGTTTGGCTTGAAGTAG & & \\
\hline$t c p /-\mathrm{F}$ & TAGCCTTAGTTCTCAGCAGGCA & \multirow[t]{2}{*}{862} & \multirow{2}{*}{$\begin{array}{l}\text { Rivera et al. } \\
2001^{9}\end{array}$} \\
\hline$t c p /-\mathrm{R}$ & GGCAATAGTGTCGAGCTCGTTA & & \\
\hline toxR-F & CCTTCGATCCCCTAAGCAATAC & \multirow[t]{2}{*}{779} & \multirow{2}{*}{$\begin{array}{l}\text { Rivera et al. } \\
2001^{9}\end{array}$} \\
\hline toxR-R & GGGTTAGCAACGATGCGTAAG & & \\
\hline $\begin{array}{l}\text { tcpA-R } \\
\text { (Classical) }\end{array}$ & TTACCAAATGCAACGCCGAATG & 620 & $\begin{array}{l}\text { Rivera et al } \\
2001^{9}\end{array}$ \\
\hline $\begin{array}{l}\text { tcpA-R } \\
\text { (El Tor) }\end{array}$ & CGAAAGCACCTTCTTTCACACGTTG & \multirow[t]{2}{*}{453} & \multirow[t]{2}{*}{$\begin{array}{l}\text { Rivera et al } \\
2001^{9}\end{array}$} \\
\hline tcpA-F & CACGATAAGAAAACCGGTCAAGAG & & \\
\hline $\begin{array}{l}\text { hylA-F } \\
\text { (Classical) }\end{array}$ & GGCAAACAGCGAAACAAATACC & 738 & $\begin{array}{l}\text { Rivera et al } \\
2001^{9}\end{array}$ \\
\hline $\begin{array}{l}\text { hyl-F } \\
\text { (EI Tor) }\end{array}$ & GAGCCGGCATTCATCTGAAT & \multirow[t]{2}{*}{481} & \multirow[t]{2}{*}{$\begin{array}{l}\text { Rivera et al } \\
2001^{9}\end{array}$} \\
\hline hylA-R & CTCAGCGGGCTAATACGGTTTA & & \\
\hline SXT-F & ATGGCGTTATCAGTTAGCTGGC & \multirow[t]{2}{*}{1035} & \multirow{2}{*}{$\begin{array}{l}\text { Bhanumathi } \\
\text { et al. } 2003^{23}\end{array}$} \\
\hline SXT-R & GCGAAGATCATGCATAGACC & & \\
\hline
\end{tabular}

Source: Publications as cited in Reference column 


\section{Results}

\section{Isolation of $V$. cholerae from environmental sources}

The coastal region had a total of 23 positive isolates out of 207 collected environmental samples (11\%) (Table 3). Kwale had the most positive isolates, accounting for $43 \%$ of positive isolates collected in this region, followed by Kilifi (35\%) and Mombasa (22\%). No samples collected in Malindi had positive isolates. The Western region had 27 positive isolates out of 199 collected samples (12\%). Homa Bay had the most positive isolates, accounting for $30 \%$ of positive isolates collected in this region, followed by Kisumu, Siaya and Rachuonyo (15\% each); Nandi Hills and Nyando (7\% each) and Bondo, Vihiga and Busia ( 4\% each).

\section{Detection of virulence genes from environmental and clinical $V$. cholerae isolates}

All clinical strains (50 of 50) were PCR positive for the gene representing the El Tor fragment for haemolysin (hylA) (Figure 2), whilst only 10\% (5 of 50) of the environmental strains were positive (Table 4). In addition, all clinical strains were PCR positive for the gene representing the Classical fragment for haemolysin as compared with 13 out of $50(26 \%)$ of the environmental strains. For environmental $V$. cholerae strains, the results of the multiplex PCR yielded positive results for tcpA (El Tor) at 12\% (6 of 50), ctxA at $8 \%$ (4 of 50$)$, zot at $24 \%$ (12 of 50), tcpI at $8 \%$ (4 of 50$)$, toxR at $22 \%$ (11 of 50) and ompU at 0\% (0 of 50) in the environmental strains. All clinical and environmental $V$. cholerae isolates $(100 \%)$ were negative for the st gene.

\begin{tabular}{lll}
\multicolumn{1}{l}{ TABLE 2: Primers pooled for multiplex PCR analysis. } \\
\hline 1st set of primers & 2nd set of primers & 3rd set of primers \\
\hline ompU & $z o t$ & $c t x A$ \\
$t o x R$ & hylA (Classical) & $t c p l$ \\
$t c p A$ (Classical) & $t c p A$ (El Tor) & - \\
hylA (El Tor) & - & -
\end{tabular}

\section{Ethical considerations}

Ethical approval was provided by the Kenya National Ethics review committee (approval number KEMRI/RES/7/3/1).

\section{Potential benefits and hazards}

There were no potential benefits or hazards to human subjects as they were not involved in the study.

\section{Trustworthiness}

\section{Reliability}

Reliability is associated with accuracy, stability, consistency and reproducibility of the research. This was ensured by peer examination and open discussion with all participants.

\section{Validity}

Validity entails ensuring that the datasets gathered or items used are pertinent or relevant to the research conducted. This was ensured by use of appropriate research design and methods.

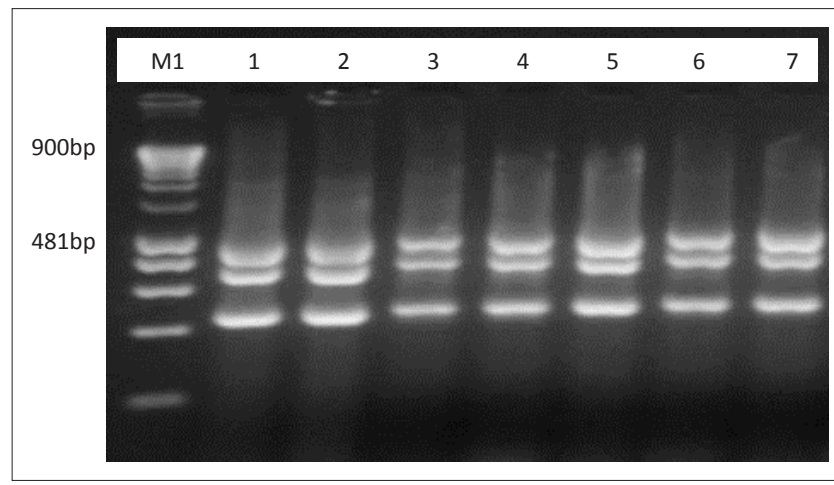

Source: Authors' own construction

M1 = 100 bp DNA Size Marker - Hyper ladder I; $1\left(230^{*}\right) ; 2\left(8673^{*}\right) ; 3(208 *) ; 4\left(8572^{*}\right)$; 5(8669*); 6(240*); 7(8667*)

ompU 869 bp, hylA 481, toxR 779 bp.

The figures in parentheses represents strain numbers.

FIGURE 2: Example amplification of $o m p U$, toxR and hylA genes in clinical Vibrio cholera.

TABLE 3: Sources of $V$. cholerae samples collected in coastal and western Kenya by region.

\begin{tabular}{|c|c|c|c|c|c|c|c|c|c|c|}
\hline \multirow[t]{2}{*}{ Regions } & \multirow{2}{*}{$\begin{array}{l}\text { Total number } \\
\text { of samples } \\
\text { collected }\end{array}$} & \multirow{2}{*}{$\begin{array}{l}\text { Positive } \\
\text { isolates }\end{array}$} & \multicolumn{8}{|c|}{ Sample sources (Number of positive isolates/Total number collected) ${ }^{1}$} \\
\hline & & & Mosses & Sediments & $\begin{array}{l}\text { Floating water } \\
\text { plants }\end{array}$ & Fish & Fish Offal & Water & Algae & Shrimp \\
\hline \multicolumn{11}{|c|}{ Coastal region } \\
\hline Kwale & 104 & 10 & - & $1 / 36$ & $4 / 24$ & $2 / 7$ & - & $0 / 38$ & $3 / 9$ & - \\
\hline Mombasa & 41 & 5 & - & $0 / 11$ & $0 / 2$ & $0 / 7$ & - & $3 / 13$ & $2 / 8$ & - \\
\hline Malindi & 44 & 0 & - & $0 / 16$ & $0 / 12$ & - & - & $0 / 14$ & $0 / 2$ & - \\
\hline Kilifi & 18 & 8 & - & $4 / 8$ & $0 / 1$ & - & - & $2 / 3$ & $2 / 6$ & - \\
\hline Total & 207 & 23 & - & 5 & 4 & 2 & 0 & 5 & 7 & - \\
\hline \multicolumn{11}{|c|}{ Western region } \\
\hline Kisumu & 59 & 4 & $1 / 5$ & $2 / 15$ & $1 / 14$ & $0 / 7$ & $0 / 5$ & $0 / 6$ & $0 / 2$ & $0 / 5$ \\
\hline Siaya & 22 & 4 & $1 / 3$ & $0 / 4$ & $0 / 4$ & $1 / 7$ & - & $2 / 4$ & - & - \\
\hline Bondo & 10 & 1 & - & $0 / 2$ & $0 / 2$ & $1 / 6$ & - & - & - & - \\
\hline Vihiga & 12 & 1 & - & $0 / 6$ & $0 / 1$ & - & - & $0 / 2$ & $1 / 3$ & - \\
\hline Nandi Hills & 26 & 2 & - & $1 / 6$ & $0 / 4$ & - & - & $0 / 5$ & $0 / 2$ & $1 / 9$ \\
\hline Busia & 24 & 1 & - & $1 / 12$ & $0 / 4$ & - & - & $0 / 3$ & $0 / 5$ & - \\
\hline Homa Bay & 25 & 8 & $1 / 6$ & $3 / 8$ & $1 / 2$ & $0 / 1$ & $1 / 3$ & - & $2 / 5$ & - \\
\hline Rachuonyo & 18 & 4 & - & $1 / 6$ & $0 / 2$ & $0 / 4$ & - & $2 / 3$ & $1 / 3$ & - \\
\hline Nyando & 3 & 2 & - & - & - & - & - & $1 / 2$ & $1 / 1$ & - \\
\hline Total & 199 & 27 & 3 & 8 & 2 & 2 & 1 & 5 & 5 & 1 \\
\hline
\end{tabular}


TABLE 4: Results of Polymerase Chain Reaction.

\begin{tabular}{|c|c|c|c|c|c|c|c|c|c|c|c|}
\hline \multirow{3}{*}{$\begin{array}{l}\text { Serial number } \\
\text { of isolate }\end{array}$} & \multirow{2}{*}{\multicolumn{3}{|c|}{$\operatorname{ctx} \Phi$}} & \multicolumn{4}{|c|}{ VPI } & \multirow{2}{*}{\multicolumn{4}{|c|}{ V. cholerae haemolysin-lecithinase-lipase cluster }} \\
\hline & & & & \multicolumn{3}{|c|}{ TCP Biogenesis } & \multirow[t]{2}{*}{ toxR } & & & & \\
\hline & ace $\dagger$ & $c t x A \dagger$ & zot & $t c p / \dagger$ & $\begin{array}{c}t c p A \\
\text { (Classical) } \dagger\end{array}$ & $\begin{array}{c}t c p A \\
(\text { EI Tor) } \dagger\end{array}$ & & $\begin{array}{c}\text { hylA } \\
\text { (Classical) } \dagger\end{array}$ & $\begin{array}{c}\text { hylA } \\
\text { (El Tor) } \dagger\end{array}$ & $s t \dagger$ & ompU† \\
\hline 8675 & + & + & + & + & - & + & + & + & + & - & + \\
\hline 1419 & + & + & + & + & - & + & + & + & + & - & + \\
\hline 8666 & + & + & + & + & - & + & + & + & + & - & + \\
\hline 247 & + & + & + & + & - & + & + & + & + & - & + \\
\hline 229 & + & + & + & + & - & + & + & + & + & - & + \\
\hline 241 & + & + & + & + & - & + & + & + & + & - & + \\
\hline 231 & + & + & + & + & - & + & + & + & + & - & + \\
\hline 8676 & + & + & + & + & - & + & + & + & + & - & + \\
\hline 202 & + & + & + & + & - & + & + & + & + & - & + \\
\hline 8679 & + & + & + & + & - & + & + & + & + & - & + \\
\hline 8678 & + & + & + & + & - & + & + & + & + & - & + \\
\hline 50 & + & + & + & + & - & + & + & + & + & - & + \\
\hline 49 & + & + & + & + & - & + & + & + & + & - & + \\
\hline 8887 & + & + & + & + & - & + & + & + & + & - & + \\
\hline 161 & + & + & + & + & - & + & + & + & + & - & + \\
\hline 8888 & + & + & + & + & - & + & + & + & + & - & + \\
\hline 8889 & + & + & + & + & - & + & + & + & + & - & + \\
\hline 44 & + & + & + & + & - & + & + & + & + & - & + \\
\hline 8884 & + & + & + & + & - & + & + & + & + & - & + \\
\hline Ruiru44 & + & + & + & + & - & + & + & + & + & - & + \\
\hline 9487 & + & + & + & + & - & + & + & + & + & - & + \\
\hline 1607 & + & + & + & + & - & + & + & + & + & - & + \\
\hline 8880 & + & + & + & + & - & + & + & + & + & - & + \\
\hline VC003 & + & + & + & + & - & + & + & + & + & - & + \\
\hline 46 & + & + & + & + & - & + & + & + & + & - & + \\
\hline 51 & + & + & + & + & - & + & + & + & + & - & + \\
\hline 9503 & + & + & + & + & - & + & + & + & + & - & + \\
\hline VC133 & + & + & + & + & - & + & + & + & + & - & + \\
\hline VC134 & + & + & + & + & - & + & + & + & + & - & + \\
\hline 64 & + & + & + & + & - & + & + & + & + & - & + \\
\hline 168 & + & + & + & + & - & + & + & + & + & - & + \\
\hline 238 & + & + & + & + & - & + & + & + & + & - & + \\
\hline 8885 & + & + & + & + & - & + & + & + & + & - & + \\
\hline 225 & + & + & + & + & - & + & + & + & + & - & + \\
\hline 8886 & + & + & + & + & - & + & + & + & + & - & + \\
\hline 8671 & + & + & + & + & - & + & + & + & + & - & + \\
\hline 207 & + & + & + & + & - & + & + & + & + & - & + \\
\hline 8667 & + & + & + & + & - & + & + & + & + & - & + \\
\hline 230 & + & + & + & + & - & + & + & + & + & - & + \\
\hline 8673 & + & + & + & + & - & + & + & + & + & - & + \\
\hline 208 & + & + & + & + & - & + & + & + & + & - & + \\
\hline 8572 & + & + & + & + & - & + & + & + & + & - & + \\
\hline 8669 & + & + & + & + & - & + & + & + & + & - & + \\
\hline 240 & + & + & + & + & - & + & + & + & + & - & + \\
\hline
\end{tabular}

Environmental isolates

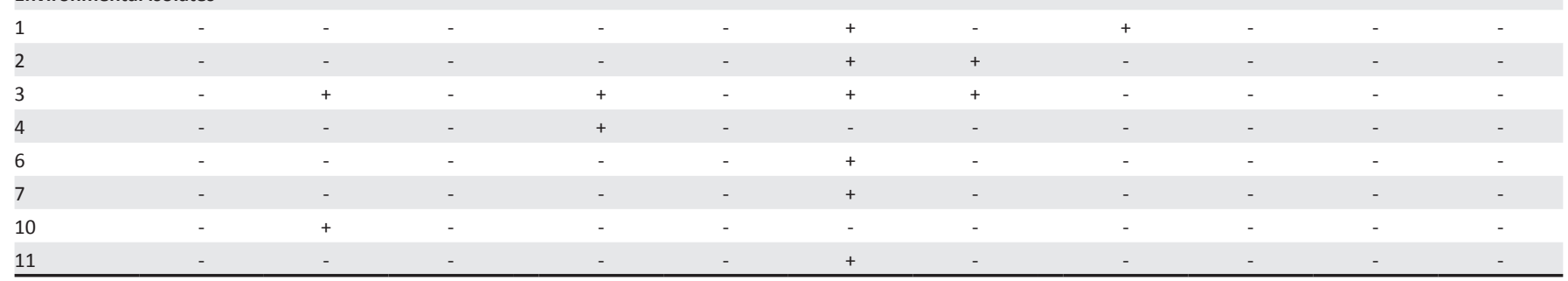

Source: Authors' own construction

Missing numbers for environmental isolates indicate samples that failed to grow or could not be used in assays after storage.

$\dagger$, Clinical Isolates.

+positive, - negative. 
TABLE 4 (Continues...): Results of Polymerase Chain Reaction.

\begin{tabular}{|c|c|c|c|c|c|c|c|c|c|c|c|}
\hline \multirow{3}{*}{$\begin{array}{l}\text { Serial number } \\
\text { of isolate }\end{array}$} & \multirow{2}{*}{\multicolumn{3}{|c|}{$\operatorname{ctx} \Phi$}} & \multicolumn{4}{|c|}{ VPI } & \multicolumn{4}{|c|}{ V. cholerae haemolysin-lecithinase-lipase cluster } \\
\hline & & & & \multicolumn{3}{|c|}{ TCP Biogenesis } & \multirow[t]{2}{*}{ toxR } & & & & \\
\hline & $a c e \dagger$ & $\operatorname{ctx} A \dagger$ & $z o t \dagger$ & $t c p / \dagger$ & $\begin{array}{c}t c p A \\
\text { (Classical) } \dagger\end{array}$ & $\begin{array}{c}t c p A \\
\text { (El Tor) } \dagger\end{array}$ & & $\begin{array}{c}\text { hylA } \\
\text { (Classical) } \dagger\end{array}$ & $\begin{array}{c}\text { hylA } \\
\text { (El Tor) } \dagger\end{array}$ & $s t \dagger$ & ompU† \\
\hline 18 & - & + & - & - & - & - & - & - & - & - & - \\
\hline 19 & - & - & + & - & - & - & - & + & - & - & - \\
\hline 22 & - & + & - & + & - & - & - & - & - & - & - \\
\hline 23 & - & - & - & - & - & - & - & - & - & - & - \\
\hline 27 & - & - & - & - & - & - & - & - & - & - & - \\
\hline 31 & - & - & - & - & - & - & - & - & - & - & - \\
\hline 32 & - & - & - & - & - & - & + & - & - & - & - \\
\hline 34 & - & - & - & - & - & - & - & - & - & - & - \\
\hline 35 & - & - & - & - & - & - & + & + & - & - & - \\
\hline 40 & - & - & - & - & - & - & - & - & - & - & - \\
\hline 43 & - & - & + & - & - & - & - & - & - & - & - \\
\hline 42 & - & - & - & - & - & - & - & + & - & - & - \\
\hline 58 & - & - & + & - & + & - & + & + & + & - & - \\
\hline 55 & - & - & - & - & + & - & - & + & - & - & - \\
\hline 36 & - & - & + & - & - & - & - & - & - & - & - \\
\hline 37 & - & - & + & - & - & - & + & - & + & - & - \\
\hline 44 & - & - & - & - & - & - & - & - & - & - & - \\
\hline 56 & - & - & - & - & - & - & - & + & - & - & - \\
\hline 46 & - & - & + & - & - & - & + & + & - & - & - \\
\hline 25 & - & - & + & - & - & - & + & + & - & - & - \\
\hline 48 & - & - & + & - & - & - & + & - & - & - & - \\
\hline 50 & - & - & - & - & - & - & + & - & - & - & - \\
\hline 29 & - & - & - & - & - & - & - & - & - & - & - \\
\hline 47 & - & - & - & - & - & - & - & - & - & - & - \\
\hline 54 & - & - & - & - & - & - & - & - & + & - & - \\
\hline 51 & - & - & - & - & - & + & - & - & + & - & - \\
\hline 56 & - & - & - & - & - & - & - & - & - & - & - \\
\hline 57 & - & - & - & - & - & - & - & + & - & - & - \\
\hline 16 & - & - & - & - & - & - & - & - & - & - & - \\
\hline 8 & - & - & - & - & - & - & - & - & + & - & - \\
\hline 15 & - & - & - & - & - & - & - & - & - & - & - \\
\hline 21 & - & - & - & - & - & - & - & - & - & - & - \\
\hline 52 & - & - & - & - & - & - & - & - & - & - & - \\
\hline 53 & - & - & - & - & - & - & - & - & - & - & - \\
\hline 33 & - & - & + & + & - & - & - & - & - & - & - \\
\hline
\end{tabular}

Source: Authors' own construction

Missing numbers for environmental isolates indicate samples that failed to grow or could not be used in assays after storage.

$\dagger$, Clinical Isolates.

+positive, - negative.

\section{Discussion}

\section{Isolation of environmental $V$. cholerae from Western and Coastal regions of Kenya}

Knowledge regarding environmental reservoirs of $V$. cholerae is of critical epidemiological and public health importance. We identified environmental reservoirs of $V$. cholera in Kenya in a disease climate consisting of few reported cases. It is therefore likely that the $V$. cholerae existing in the environment amplify during the off-season to cause epidemics.

\section{Prevalence of virulence factors in environmental and clinical isolates of $\mathrm{V}$. cholerae}

In this study, the occurrence and distribution of selected virulence-associated genes in environmental and clinical strains of $V$. cholerae collected in Kenya were demonstrated.
Environmental studies of $V$. cholerae have been done with the expectation that the $V$. cholerae strains possessing the entire complement of virulence genes would be isolated. In this study, as in previous similar studies, this did not happen. This can be explained by the fact that virulence genes are dispersed amongst environmental strains of $V$. cholerae and may be ferried about in mobile genetic elements. These genotypes of environmental $V$. cholerae are said to act as reservoirs for the virulence factors and potential mixing and matching leads to the formation of new pathogenic strains. ${ }^{11}$ Two multiplex PCR assays revealed that all of the clinical strains were positive for ctx, zot, tcpI, and ace, as well as hlyA (both El Tor and Classical), ompU and the toxR gene, suggesting the presence of an intact core toxin region in all isolates. These genes are found together and represent the genome of filamentous bacteriophage СТХФ. This implies that they possessed a СТХФ and tcp pathogenicity island. 
The pilus colonisation factor TCP acts as a receptor for СТХ $\Phi$, which can infect non-toxigenic $V$. cholerae, leading to the emergence of new toxigenic strains of $V$. cholerae. The genes that encode the cholera toxin subunits $\operatorname{ct} x A$ and $\operatorname{ct} x B$ are localised to a CTX genetic element which is made up of a $4.6 \mathrm{Kbp}$ central core region and a $2.4 \mathrm{Kbp}$ repetitive sequence known as RS2.12 Classical strains of $V$. cholerae O1 contain two copies of the CTX element, one on each chromosome. Waldor and Mekalanos ${ }^{13}$ were able to show that CTX is a filamentous bacteriophage related to the M13 coliphage. ${ }^{12}$ Faruque, Alberts and Mekalanos $^{14}$ reported that an environmental $V$. cholerae and two $V$. mimicus strains, all of which lacked TCP, were capable of being infected by СТХФ.

The $V$. cholerae pathogenicity island (VPI) is $39.5 \mathrm{~kb}$ in size and contains genes associated with virulence (TCP-ACF cluster), the regulation of virulence (toxT and tcpP/H), the regulation of chemotaxis (tcpI or $a c f B$ ) and mobility (int and orfl). ${ }^{9}$ The genes encoding TCP have been suggested to be part of a larger genetic element consisting of a cluster of genes. The tcpA El Tor gene was positive in all clinical $V$. cholerae isolates and in $12 \%$ of environmental isolates in the current study, and the tcpA Classical gene was negative in all isolates.

Harkey et al. ${ }^{15}$ suggested that regulators such as TcpI that act downstream of ToxR and ToxT may function to fine tune the expression of the TCP virulence determinant throughout the pathogenic cycle of $V$. cholerae. The TcpI encoding gene present in $8 \%$ of our environmental strains may thus have some other physiological functions as well. ${ }^{16}$

The outer membrane protein, OmpU, was reported to be a potential adherence factor for $V$. cholerae. In this study, the gene was present in all of the $V$. cholerae strains of clinical origin that were tested, and negative in $V$. cholerae strains isolated from the environment. The haemolysin gene has been employed to differentiate between the two biotypes of $V$. cholera O1. Two primer sets for the Classical and El Tor biotypes were used in this study. The $V$. cholerae strains of clinical origin from both biotypes were positive for the hylA gene. Environmental isolates were $26 \%$ positive for haemolysin of the Classical biotype and $10 \%$ for the El Tor biotype. This phenomenon of detecting both fragments encoding for hylA specific to both the Classical and the El Tor biotypes in one isolate was observed in a similar study. ${ }^{17}$ NAG-ST in $V$. cholera $\mathrm{O} 1$ strains that is closely related to the heat-stable toxins produced by enterotoxigenic E. coli and other enteric pathogens was defined. ${ }^{18}$ The heat-stable enterotoxin production by the st genes was tested and none of the $V$. cholerae strains (of either environmental or clinical origin) were positive.

The regulation and expression of genes for growth and survival depend on the regulon ToxR, which is regulated by a cascade mechanism involving three known components: ToxR, ToxS and ToxT. ToxR, a 32-kDa transmembrane protein, is the master regulator and its expression is dependent upon environmental growth conditions (incubation temperature, $\mathrm{pH}$, osmolarity, bile salts, oxygen tension, hydrostatic pressure and amino acid composition of the medium. ${ }^{19}$ The toxR gene encodes a transcriptional activator controlling CT gene expression (ctxA), TCP biogenesis (tcpA), outer membrane protein expression (ompU), and at least 17 distinct genes in the $\mathrm{O} 139$ and $\mathrm{O} 1$ strains. ${ }^{20}$ In this study, the presence of the toxR gene was verified in all $V$. cholerae isolates of clinical origin and in $24 \%$ of the environmental isolates.

\section{Conclusion}

The implications of finding $V$. cholerae in environmental sources with virulence genes also found in clinical isolates are significant. The possibility is that this may lead to an epidemic strain arising through gene transfer that links genes that facilitate transmission in human populations, whilst those that foster persistence are proliferating in nearby environmental niches. Gene interactions are therefore important to understanding the epidemiology and persistence of virulence factors and subsequent epidemic outbreaks. Proper hygiene and fish-handling techniques should be ensured to cut the transmission from environmental sources to humans.

\section{Acknowledgements}

The authors would wish to thank the Disease Surveillance Unit of the Ministry of Public Health and Sanitation, Kenya for providing information on past cholera outbreaks. We also thank KEMRI-CMR members of staff for their support in this work.

\section{Conflicting interests}

The authors declare that they have no financial or personal relationship(s) that may have inappropriately influenced them in writing this article.

\section{Authors' contributions}

R.K. (Institute of Tropical Medicine and Infectious Disease, Jomo Kenyatta University of Agriculture and Technology [JKUAT]) analysed the data and drafted the manuscript. S.K. (CMR-KEMRI), W.S. (CMR-KEMRI) and A.W.T.M. (Faculty of Science, JKUAT) supervised the carrying out of this work. J.N.K. (CMR-KEMRI) supervised the laboratory protocols and execution of experiments.

\section{References}

1. World Health Organization. Weekly Epidemiol Rec. 2004;79:236-244.

2. World Health Organization. Global task force on Cholera Control. Cholera Country Profile [document on the Internet]. [cited April]. Available from: http://www. who.int/cholera/countries/KenyaCountryProfile2010.pdf

3. Nehebay S. Cholera breaks out in Kenya's Dadaab refugee camp: UN [page on the Internet]. c2011 [cited 2012 Sep 12]. Available from http://www.reuters.com/ article/2011/11/15/ozatp-kenya-un-refugees-idAFJOE7AEODR20111115

4. Colwell RR, Tamlin ML, Brayton PR, et al. Environmental aspects of Vibrio cholerae in transmission of cholera. In: Sack RB, Zinnaka Y, editors. Advances in research on cholera and related diarrhoea. 7th ed. Tokyo: KTK Scientific Publishers, 1990; pp. 327-343.

5. Mutreja A, Kim DW, Thomson NR, et al. Evidence for several waves of global transmission in the seventh cholera pandemic. Nature 2011;477(7365):462-465. $\mathrm{http}: / / \mathrm{dx}$.doi.org/10.1038/nature10392 
6. World Health Organization. Cholera annual report 2011. Weekly Epidemiol Rec. 2012;87(31-32), 289-304.

7. Mohamed AA, Oundo J, Kariuki SM, et al. Molecular epidemiology of geographically dispersed Vibrio cholerae, Kenya, January 2009-May 2010. Emerging Infectious Diseases. 2012;18(6):n.p..

8. Huq A, Sack RB, Nizam A, et al. Critical factors influencing the occurrence of Vibrio cholerae in the environment of Bangladesh. Appl Environ Microbio 2005;71(8):4645-4654. http://dx.doi.org/10.1128/AEM.71.8.4645-4654.2005

9. Rivera IN, Chun J, Huq A, et al. Genotypes associated with virulence in environmental isolates of Vibrio cholerae. Appl Environ Microbiol. 2001;67(6):2421-2429. http://dx.doi.org/10.1128/AEM.67.6.2421-2429.2001

10. Fields PI, Popovic $\mathrm{T}$, Wachsmuth $\mathrm{K}$, et al. Use of polymerase chain reaction for detection of toxigenic Vibrio cholerae 01 strains from the Latin American cholera epidemic. J Clin Microbiol. 1992;30(8):2118-2121.

11. Karaolis DKR. A Vibrio cholerae pathogenicity island associated with epidemic and pandemic strains. Proc Natl Acad Sci U S A. 1998;95(6):3134-3139. http:// dx.doi.org/10.1073/pnas.95.6.3134

12. Garg P, Nandy RK, Chaudhury P, et al. Emergence of Vibrio cholerae O1 Biotype $E$ Tor serotype Inaba from the prevailing 01 Ogawa serotype strains in India. $\mathrm{J}$ Clin Microbiol. 2000;38(11):4249-4253.

13. Waldor MK, Mekalanos JJ. Lysogenic conversion by a filamentous phage encoding cholera toxin. Science. 1996;272:1910-1914. http://dx.doi. org/10.1126/science.272.5270.1910

14. Faruque SM, Albert MJ and Mekalanos JJ. Epidemiology, genetics and ecology of toxigenic Vibrio cholerae. Microbiol Mol Biol Rev. 1998;62:1301-1314.

15. Harkey CW, Everiss KD, Peterson KM. The Vibrio cholerae toxin-coregulatedpilus gene tcpl encodes a homolog of methyl-accepting chemotaxis proteins. Infect Immun. 1994:62(7):2669-2678.
16. Chakraborty S, Mukhopadhyay AK, Bhadra RK, et al. Virulence genes in environmental strains of Vibrio cholerae Appl Environ Microbiol. 2000:66(9):4022-4028. http://dx.doi.org/10.1128/AEM.66.9.4022-4028.2000

17. Singh DV, Matte MH, Matte GR, et al. Molecular analysis of Vibrio cholerae $\mathrm{O1}$ 0139, non-01, and non-0139 strains: Clonal relationships between clinical and environmental isolates. Appl Environ Microbiol. 2001;67(2):910-921. http:// dx.doi.org/10.1128/AEM.67.2.910-921.2001

18. Arita MT, Honda T, Miwatani T, et al. Purification and characterization of a heatstable enterotoxin of Vibrio mimicus. FEMS Microbiol Lett. 1991;63(1):105-110. http://dx.doi.org/10.1111/j.1574-6968.1991.tb04513.x

19. DiRita VJ. Co-ordinate expression of virulence genes by ToxR in Vibrio cholerae. Mol Microbiol. 1992;6(4):451-458. http://dx.doi. org/10.1111/j.1365-2958.1992.tb01489.x

20. Herrington DA. Toxin, toxin-coregulated pili, and the toxR regulon are essential for Vibrio cholerae pathogenesis in humans. J Exp Med. 1998;168(4):14871492. http://dx.doi.org/10.1084/jem.168.4.1487

21. Shi L, Miyoshi S, Hiura M, et al. 1998. Detection of genes encoding cholera toxin (CT), zonula occludens toxin (ZOT), accessory cholera enterotoxin (ACE) and heat-stable enterotoxin (ST) in Vibrio mimicus clinical strains. Microbio Immunol. 1998;42(12):823-828. http://dx.doi.org/10.1111/j.1348-0421.1998. tb02357.x

22. Vicente AC, Coelho AM, Salles CA. Detection of Vibrio cholerae and V. mimicus heat-stable toxin gene sequence by PCR. J Med Microbiol. 1997;46(5):398-402. http://dx.doi.org/10.1099/00222615-46-5-398

23. Bhanumathi R, Sabeena $F$, Isac SR, et al. Molecular characterization of Vibrio cholerae 0139 bengal isolated from water and the aquatic plant Eichhornia crassipes in the River Ganga, Varanasi, India. Appl Environ Microbiol. 2003:69:2389-2394. http://dx.doi.org/10.1128/AEM.69.4.2389-2394.2003 